\title{
Gastric Myeloid Sarcoma Mimicking a Scirrhous Gastric Cancer
}

\author{
Yoko Taminishi-Katsuragawa ${ }^{1}$, Yuji Shimura ${ }^{1,2}$, Yu inoue ${ }^{1}$, Yayoi Matsumura-Kimoto ${ }^{1}$, \\ Taku Tsukamoto ${ }^{1}$, Shinsuke Mizutani ${ }^{1}$, Tsutomu Kobayashi ${ }^{1}$, Naoko Takeda-Miyata ${ }^{3}$, \\ Ayako Nishimura $^{3}$, Kojiro Takatsuka ${ }^{4}$ and Junya Kuroda ${ }^{1}$
}

\begin{abstract}
:
Myeloid sarcoma (MS) is a relatively rare manifestation of myeloid neoplasms at sites other than the bone marrow. The rarity of gastrointestinal (GI) MS is attributed to certain factors, such as misdetection due to insufficient endoscopic assessments at the initial presentation with acute myeloid leukemia (AML) as well as the difficulty of making a histologic assessment of leukemic involvement of the GI tract. We herein report a case of AML with gastric involvement and discuss the importance of screening examinations and therapies considering the location of MS and the data of cytogenetic and molecular mutation.
\end{abstract}

Key words: myeloid sarcoma (MS), gastric MS, NPM1 mutation

(Intern Med Advance Publication)

(DOI: 10.2169/internalmedicine.7986-21)

\section{Introduction}

Myeloid sarcoma (MS) is a relatively rare extramedullary manifestation of myeloid neoplasms defined as a tumor mass consisting of myeloid neoplastic cells at sites other than the bone marrow (BM) (1-3). Although skin, soft tissues and lymph nodes are relatively common sites of MS, gastrointestinal (GI) tract involvement has been rare (4).

We herein report a case of acute myeloid leukemia (AML) with gastric involvement that macroscopically mimicked scirrhous gastric cancer (SGC).

\section{Case Report}

A 66-year-old man from our institute presented with symptoms of stomachache and shortness of breath during exertion. His medical history included hypertension, insomnia, and a previous infection with hepatitis $\mathrm{C}$ virus that had been successfully cured by interferon therapy.

Upper gastrointestinal endoscopy revealed the presence of multifocal ulcers and fold thickening in the body of the stomach Fig. 1A, whereas computed tomography (CT) identified diffuse wall thickening of the stomach and lymphadenopathy around the stomach (Fig. 2) as well as consolidative shadow in the lower field of the right lung (data not shown). Although these findings suggested that the patient had been affected by SGC with pneumonia, the biopsied specimen from the gastric ulcer only showed inflammatory granulation.

Unexpectedly, at the same time, the blood test revealed marked leukocytosis with bicytopenia of anemia and thrombocytopenia; the white blood cell count was elevated to 31.2 $\times 10^{9} / \mathrm{L}$ (normal range: $3.6-8.8 \times 10^{9} / \mathrm{L}$ ) containing $89.0 \%$ abnormal myeloblasts, whereas the hemoglobin level and platelet count had decreased to $6.2 \mathrm{~g} / \mathrm{dL}(12.5-17.3 \mathrm{~g} / \mathrm{dL})$ and $39.0 \times 10^{9} / \mathrm{L}\left(150.0-150.0 \times 10^{9} / \mathrm{L}\right)$, respectively. A BM analysis showed hypercellular BM with an all nucleated cell count of $215 \times 10^{9} / \mathrm{L}$, including $76.4 \%$ leukemic cells that were positive for $\mathrm{CD} 11 \mathrm{~b}, \mathrm{CD} 13, \mathrm{CD} 33, \mathrm{CD} 117$, and myeloperoxidase (MPO) but negative for $\mathrm{CD} 15, \mathrm{CD} 34$, and HLA-DR Fig. 3A. A chromosome analysis of BM cells

\footnotetext{
${ }^{1}$ Division of Hematology and Oncology, Department of Medicine, Kyoto Prefectural University of Medicine, Japan, ${ }^{2}$ Department of Blood Transfusion, Kyoto Prefectural University of Medicine, Japan, ${ }^{3}$ Department of Surgical Pathology, Kyoto Prefectural University of Medicine, Japan and ${ }^{4}$ Maiduru Kyoritsu Clinic, Japan

Received: May 17, 2021; Accepted: August 11, 2021; Advance Publication by J-STAGE: October 5, 2021

Correspondence to Dr. Yuji Shimura, yshimura@koto.kpu-m.ac.jp
} 


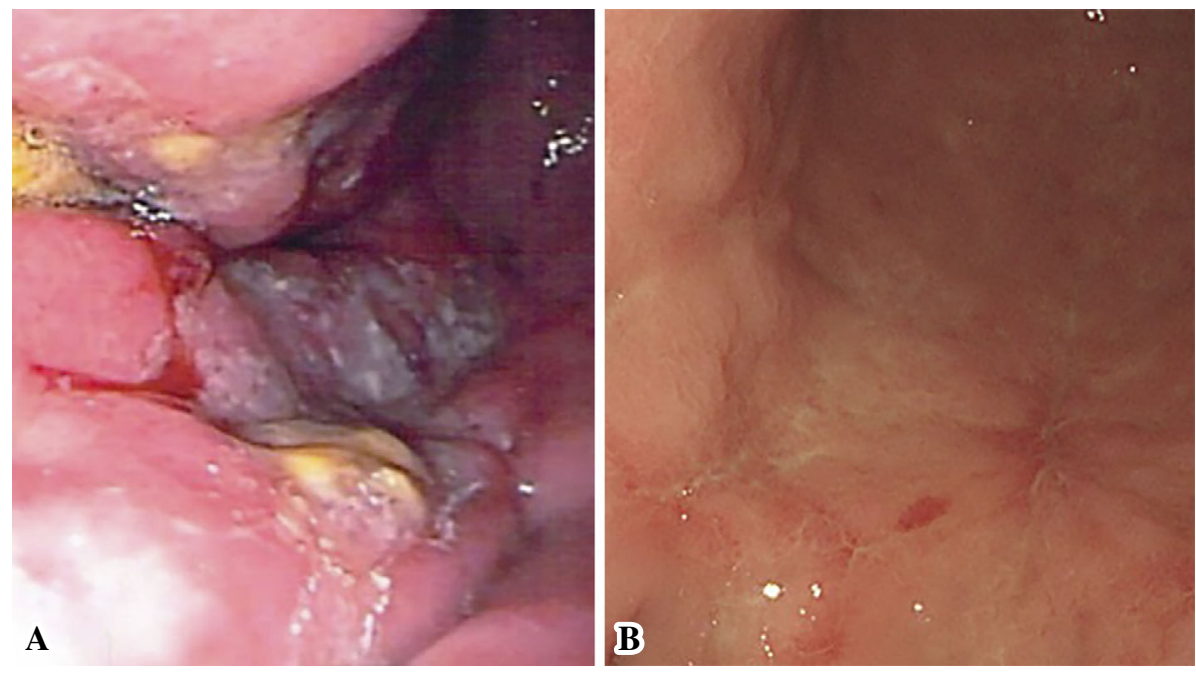

Figure 1. Endoscopic appearance of the gastric lesion. (A) Before therapy. (B) After re-induction therapy.

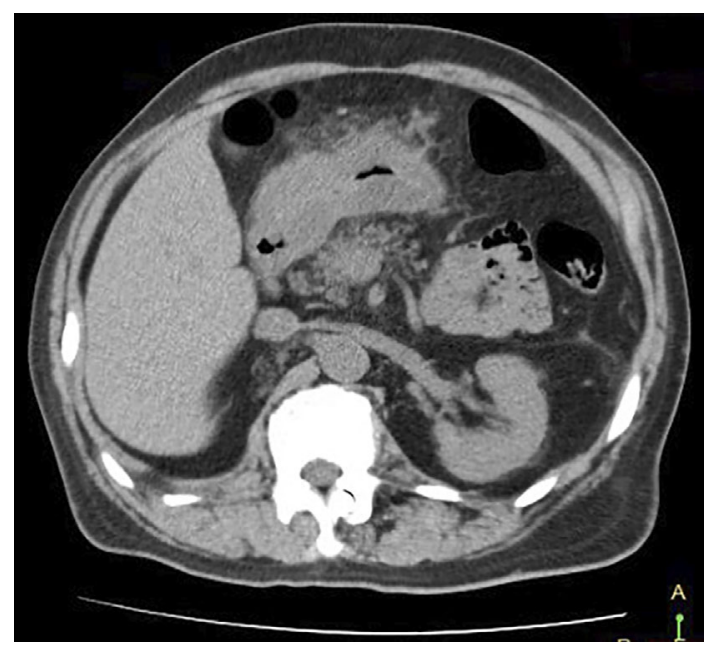

Figure 2. CT revealed diffuse wall thickening of the stomach and lymphadenopathy around the stomach.

showed a normal karyotype, whereas a genetic examination revealed that the leukemic cells were positive for a gene mutation of nucleophosmin 1 (NPM1) but negative for any abnormality in the FMS-like tyrosine kinase 3 gene. Furthermore, a serological examination detected an elevated Creactive protein level at $13.3 \mathrm{mg} / \mathrm{dL}(<0.3 \mathrm{mg} / \mathrm{dL})$ and $\mathrm{b}$-dglucan level at $105.7 \mathrm{pg} / \mathrm{mL}(<20 \mathrm{pg} / \mathrm{mL})$. Other laboratory tests showed no major abnormalities. Given these findings, the patient was diagnosed with AML with mutated NPM1 potentially complicated by fungal pneumonia.

In the absence of a confirmatory diagnosis of a gastric lesion, intensive systemic induction chemotherapy consisting of $12 \mathrm{mg} / \mathrm{m}^{2}$ of idarubicin (Days 1-3) and the continuous infusion of $100 \mathrm{mg} / \mathrm{m}^{2}$ of cytarabine (Days 1-7) was initiated, successfully inducing hematologic complete remission (CR).

Furthermore, the simultaneous administration of antifungal agents successfully controlled fungal pneumonia. However, the endoscopic examination showed a residual gastric lesion after the first cycle of chemotherapy Fig. 1B, and the biopsied specimen of the gastric lesion revealed the presence of extensive infiltration of MPO-positive leukemic cells Fig. 3B-D. Re-induction therapy with the same regimen successfully induced the remission of the gastric lesion Fig. 1B with preserved CR, which was maintained after four subsequent courses of consolidation chemotherapies consisting of several types of anthracyclines and cytarabine.

The patient subsequently received additional consolidative 24-Gy irradiation for the gastric lesion, and CR continued to be maintained.

\section{Discussion}

MS occurs with chronic myelogenous leukemia, myelodysplastic syndrome, and myeloproliferative neoplasm, even in the absence of BM involvement (2). Isolated MS lesions have been frequently reported at relapse after allogeneic hematopoietic cell transplantation for AML, although the rate of MS with or without BM involvement at the diagnosis is quite rare (2). Furthermore, while skin, soft tissues, and lymph nodes are reported to be commonly involved, only a few case reports have described MS with both GI tract and $\mathrm{BM}$ involvement (2, 5, 6, Tables 1 and 2). However, the true incidence of MS of the GI tract has yet to be verified, especially at the onset of AML.

One possible reason for the low incidence of GI involvement of MS with systemic AML is due to misdetection as a result of insufficient endoscopic assessments at the initial presentation with AML. GI involvement was incidentally detected in our patient, as an endoscopic examination was performed due to the patient's initial chief complaint. Another potential reason may be the difficulty in performing a histologic assessment of the leukemic involvement of the GI tract. As in the present patient, it is generally difficult to perform a repeated biopsy for the leukemic involvement of the GI tract, which often constitutes submucosal lesions in patients with AML accompanied by thrombocytopenia and 


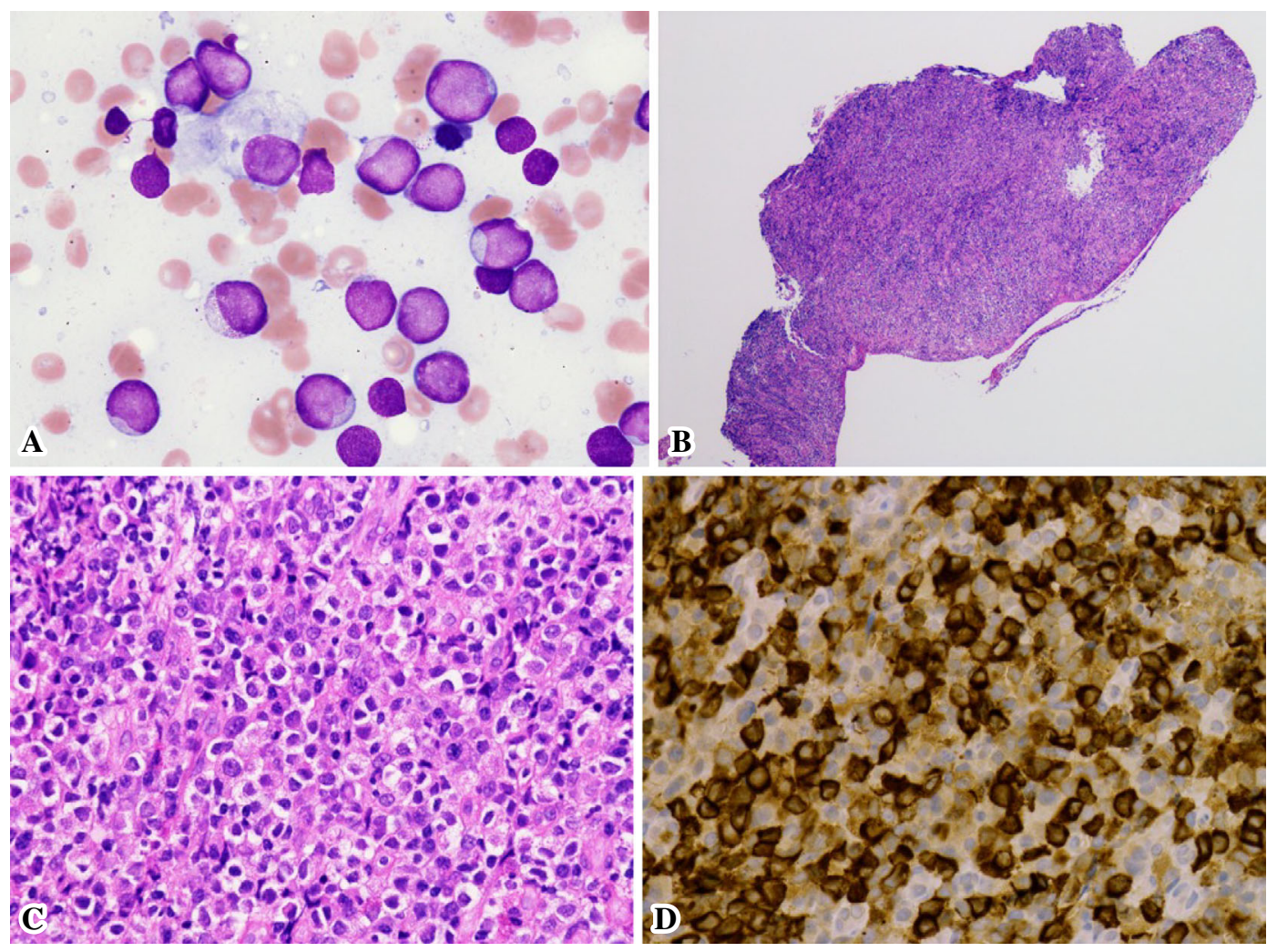

Figure 3. Image of bone marrow smear [(A) Wright and Giemsa staining, $\times 1,000]$ and gastric biopsy specimens [(B) Hematoxylin and Eosin (H\&E) staining, $\times 40$; (C) H\&E staining, $\times 400$; (D) myeloperoxidase (MPO) staining, $\times 400]$.

Table 1. List of Studies Regarding Newly Diagnosed MS Patients with BM Involvement.

\begin{tabular}{|c|c|c|c|c|c|}
\hline Author & Study type & $\begin{array}{l}\text { Patient } \\
\text { number }\end{array}$ & $\begin{array}{l}\text { The rate of MS } \\
\text { involvement in } \\
\text { AML patients }\end{array}$ & GI tract lesion & Comments \\
\hline Ref.7 & $\begin{array}{l}\text { Review of case } \\
\text { reports }\end{array}$ & 207 & - & $3 \%$ & Only cases of MS with BM involvement \\
\hline Ref.9 & $\begin{array}{l}\text { Single institute, } \\
\text { retrospective }\end{array}$ & 11 & - & one patient & Only cases of MS with BM involvement \\
\hline Ref.10 & $\begin{array}{l}\text { Collected from } \\
\text { clinical studies }\end{array}$ & 3,240 & $23.7 \%(0.2 \%)$ & no description & $\begin{array}{l}\text { Most cases were diagnosed by physical examinations or imaging } \\
\text { studies. Pathologically confirmed MS cases was only } 0.2 \% \text {. }\end{array}$ \\
\hline Ref.11 & $\begin{array}{l}\text { Collected from } \\
\text { database }\end{array}$ & 477 & $2.50 \%$ & no description & Patients treated with standard induction regimen were reviewed. \\
\hline
\end{tabular}

MS: myeloid sarcoma, BM: bone marrow

Table 2. List of Case Reports of Newly Diagnosed MS Patients with GI Tract Lesions and BM Involvement.

\begin{tabular}{lccccc}
\hline Author & Patient & AML type & GI tract & Therapy & Prognosis \\
\hline Ref.8 & $33 \mathrm{~F}$ & AML-M4 & Stomach & Chemotherapy & relapse at 9M \\
Re.12 & 25F & AML-M4 & Stomach & Chemotherapy & maintain CR \\
\hline
\end{tabular}

MS: myeloid sarcoma, GI: gastrointestinal, BM: bone marrow

coagulation abnormality, which carry a high risk for bleeding. GI involvement has been detected in up to $25 \%$ of AML cases at postmortem autopsies. Given the difficulty of GI tract screening at the onset of AML, this indicates the need for GI screening even after the achievement of hematologic CR by chemotherapy.
Although various aspects of the gross appearance of MS in the GI tract have been reported, including an ulcerative form, isolated mass, nodular formation, and even normal mucosal features $(5,6,12)$, gastric MS mimicking SGC as seen in the present case has been extremely rare. Therefore, careful endoscopic observation and histopathologic assess- 
ments, sometimes with rigorous biopsies, are needed for the diagnosis of gastric MS. Although the detailed molecular mechanisms underlying the extramedullary proliferation of leukemic cells remain unclear with MS, the NPM1 mutation, as seen in our case, has been reported to be relatively frequent with MS $(9,10,13-16)$. It has also been reported that the ectopic overexpression of mutated NPM1 potentiates leukemic cells with a more adhesive, migratory, and invasive phenotype (16). Thus, further studies should evaluate the value of GI screening in AML patients with an NPM mutation.

While patients with isolated MS may have better survival outcomes than those with MS with systemic AML $(2,10,17)$, the impact of the MS on the prognosis of systemic AML is controversial (2). One retrospective study reported there was no clinical difference between MS with and without AML (11). Recently, the prognosis of MS has seemed to differ depending on the involved site (2). For example, isolated MS of the GI tract has been reported to have a better prognosis than all isolated MS (overall survival at 6 months: $74 \%$ vs. $57 \%$ ), whereas isolated MS of the nervous system or soft tissue shows a poor clinical outcome $(2,17)$. Information on the treatment and prognosis of MS of the GI tract with systemic AML is limited, but several reports have suggested the frequent incorporation of local managements, including surgery and irradiation, in addition to systemic chemotherapy $(8,12)$. Furthermore, radiation therapy has been the preferred treatment method for localized lesions and elderly patients, and a relatively low dose (10-24 Gy) of irradiation has been reported to be effective at controlling MS (18). Therefore, we administered focal irradiation to the gastric lesion, even after the achievement of CR, as consolidation therapy, because gastric MS lesions were suggested to be less chemo-sensitive than BM leukemic cells at the first induction therapy. In addition, we decided not to perform allogeneic hematopoietic cell transplantation due to the genetic risk of our case $(19,20)$. Therefore, minimal residual monitoring by quantitative polymerase chain reaction of NPM1-mutant transcripts may be important for our patient (20). Furthermore, should he relapse, an examination for genetic abnormalities will be necessary again in order to determine the presence of additional genetic mutations related to the relapse.

In conclusion, we reported a rare case of NPM1-mutated AML with gastric MS macroscopically mimicking SGC. Screening examinations before induction therapies are important, and combined and individualized therapies considering the location of extramedullary lesions and the data of cytogenetic and molecular mutations are necessary.

\section{The authors state that they have no Conflict of Interest (COI).}

\section{Acknowledgments}

We are especially grateful to the patient and his family for giving us consent to perform all experiments associated with his case.

\section{Ethical approval}

All procedures involving the patient were performed in accordance with the ethical standards of the institutional and/or national research committee and the 1964 Declaration of Helsinki and its later amendments or comparable ethical standards.

\section{Informed consent}

Informed consent was obtained from the patient for the procedures used in the study and for the publication of the case report.

\section{References}

1. Wilson CS, Medeiros LJ. Extramedullary Manifestations of Myeloid Neoplasms. Am J Clin Pathol 144: 219-239, 2015.

2. Shallis RM, Gale RP, Lazarus HM, Roberts KB, Xu ML, Seropian SE, et al. Myeloid sarcoma, chloroma, or extramedullary acute myeloid leukemia tumor: A tale of misnomers, controversy and the unresolved. Blood Rev 100773, 2020.

3. Almond LM, Charalampakis M, Ford SJ, Gourevitch D, Desai A. Myeloid Sarcoma: Presentation, Diagnosis, and Treatment. Clin Lymphoma Myeloma Leukemia 17: 263-267, 2017.

4. Ullman DI, Dorn D, Jones JA, Fasciano D, Ping Z, Kanakis C, et al. Clinicopathological and molecular characteristics of extramedullary acute myeloid leukaemia. Histopathology 75: 185-192, 2019.

5. Huang X-L, Tao J, Li J-Z, Chen X-L, Chen J-N, Shao C-K, et al. Gastric myeloid sarcoma without acute myeloblastic leukemia. World J Gastroentero 21: 2242-2248, 2015.

6. Vachhani P, Bose P. Isolated Gastric Myeloid Sarcoma: A Case Report and Review of the Literature. Case Reports Hematology 2014: 1-4, 2014.

7. Byrd JC, Edenfield WJ, Shields DJ, Dawson NA. Extramedullary myeloid cell tumors in acute nonlymphocytic leukemia: a clinical review. J Clin Oncol 13: 1800-1816, 1995.

8. Zhou W, Vasquez JC, O’Donnell MR, Paz BI. Clinical manifestations of gastrointestinal granulocytic sarcoma requiring surgical treatment. Am Surg 67: 764-766, 2001.

9. Kashofer K, Gornicec M, Lind K, Caraffini V, Schauer S, Beham-Schmid C, et al. Detection of prognostically relevant mutations and translocations in myeloid sarcoma by next generation sequencing. Leukemia Lymphoma 59: 1-4, 2017.

10. Ganzel C, Manola J, Douer D, Rowe JM, Fernandez HF, Paietta EM, et al. Extramedullary Disease in Adult Acute Myeloid Leukemia Is Common but Lacks Independent Significance: Analysis of Patients in ECOG-ACRIN Cancer Research Group Trials, 19802008. J Clin Oncol 34: 3544-3553, 2016.

11. Earl M, Fu A, Kalaycio M, Advani A, Saunthararajah Y, et al. Outcomes In Acute Myeloid Leukemia (AML) Patients Diagnosed With Myeloid Sarcoma with and without Bone Marrow Involvement. Blood 116: 2165, 2010.

12. Sekaran A, Darisetty S, Lakhtakia S, Ramchandani M, Reddy DN. Granulocytic Sarcoma of the Stomach Presenting as Dysphagia during Pregnancy. Case Reports Gastrointest Medicine 2011: 627549, 2011.

13. Solh M, Solomon S, Morris L, Holland K, Bashey A. Extramedullary acute myelogenous leukemia. Blood Rev 30: 333-339, 2016.

14. Ohanian M, Faderl S, Ravandi F, Pemmaraju N, Garcia-Manero G, Cortes $\mathrm{J}$, et al. Is acute myeloid leukemia a liquid tumor? Int $\mathrm{J}$ Cancer 133: 534-543, 2013.

15. Li Z, Stolzel F, Onel K, Sukhanova M, Mizra MK, Yap KL, et al. Next-generation sequencing reveals clinically actionable molecular markers in myeloid sarcoma. Leukemia 29: 2113-2116, 2015.

16. Xian J, Shao H, Chen X, Zhang S, Quan J, Zou Q, et al. Nucleophosmin mutants promote adhesion, migration and invasion of hu- 
man leukemia THP-1 cells through MMPs up-regulation via Ras/ ERK MAPK signaling. Int J Biol Sci 12: 144-155, 2016.

17. Movassaghian M, Brunner AM, Blonquist TM, Sadrzadeh $\mathrm{H}$, Bhatia A, Perry AM, et al. Presentation and outcomes among patients with isolated myeloid sarcoma: a Surveillance, Epidemiology, and End Results database analysis. Leukemia Lymphoma 56: 1698-1703, 2014

18. Bakst R, Wolden S, Yahalom J. Radiation Therapy for Chloroma (Granulocytic Sarcoma). Int J Radiat Oncol Biology Phys 82: 1816-1822, 2012.
19. Herold T, Rothenberg-Thurley M, Grunwald VV, Janke H, Goerlich D, Sauerland MC, et al. Validation and refinement of the revised 2017 European LeukemiaNet genetic risk stratification of acute myeloid leukemia. Leukemia 34: 3161-3172, 2020.

20. Falini B, Brunetti L, Martelli MP. How I diagnose and treat NPM 1-mutated AML. Blood 137: 589-599, 2021.

The Internal Medicine is an Open Access journal distributed under the Creative Commons Attribution-NonCommercial-NoDerivatives 4.0 International License. To view the details of this license, please visit (https://creativecommons.org/licenses/ by-nc-nd/4.0/).

(C) The Japanese Society of Internal Medicine Intern Med Advance Publication 